\title{
Análise comparativa dos quadros fonológicos dos crioulos autóctones do golfo da Guiné
}

DOI: http://dx.doi.org/10.21165/el.v48i3.2229

\author{
Manuele Bandeira' \\ Shirley Freitas ${ }^{2}$
}

\section{Resumo}

Este estudo propõe uma análise comparativa das fonologias do santome, lung'le, angolar e o fa d'Ambô. A formação dessas línguas autóctones da região insular do golfo da Guiné, na África Ocidental, está diretamente relacionada a uma língua ancestral, o protocrioulo do golfo da Guiné (PGG). Com base no método histórico-comparativo, o presente estudo comparou os sistemas fonológicos das quatro línguas-filhas do PGG. Na comparação dos inventários consonantais, todas as línguas compartilham treze fonemas (/p b t d k g $f$ v I m n w j/) e divergem quanto a treze fonemas (/kp gb s z $\theta \partial \int 3 \kappa \mathrm{rt} d z \mathrm{n} /$ ). Os sistemas de vogais orais simples, por seu turno, convergem em todos os pontos, ao passo que os sistemas de vogais longas - idênticos em fa d'ambô, em lung'ie e em angolar - diferem apenas do santome que não apresenta os referidos segmentos. As divergências entre os quadros de fonemas refletiram os caminhos tomados pelas quatro línguas a partir da especiação do PGG após a separação geográfica de seus falantes e a consequente formação de cada língua.

Palavras-chave: crioulos portugueses; Golfo da Guiné; fonologia; comparação.

1 Universidade da Integração Internacional da Lusofonia Afro-Brasileira (UNILAB), São Francisco do Conde, Bahia, Brasil; manuelebandeira@unilab.edu.br; http://orcid.org/0000-0002-3163-0377

2 Universidade da Integração Internacional da Lusofonia Afro-Brasileira (UNILAB), São Francisco do Conde, Bahia, Brasil; shirleyfreitas@unilab.edu.br; http://orcid.org/0000-0001-6124-8067 


\title{
Comparative analysis of the phonological tables of native creole languages of the Gulf of Guinea
}

\begin{abstract}
This study proposes a comparative analysis of the phonologies of Santome, Lung'le, Angolar and Fa d'Ambô. The formation of these indigenous languages in the island region of the Gulf of Guinea in West Africa is directly related to an ancestral language, the protocreole of the Gulf of Guinea (PGG). Based on the historical-comparative method, the present study compares the phonological systems of the four daughter languages of PGG. In comparing consonant inventories, all languages share thirteen phonemes (/p b $\mathrm{t} \mathrm{d} \mathrm{k} \mathrm{g} \mathrm{f} \mathrm{v} \mathrm{I} \mathrm{m} \mathrm{n} \mathrm{w} \mathrm{j/)} \mathrm{and} \mathrm{differ} \mathrm{in} \mathrm{thirteen} \mathrm{phonemes} \mathrm{(/kp} \mathrm{gb} \mathrm{s} \mathrm{z} \theta$ ə $3 \kappa \mathrm{rt} d \mathrm{~d}_{3} \mathrm{n} /$ ). Simple oral vowel systems, in turn, converge at all points. Long vowel systems - identical in Fa d'ambô, Lung'ie and Angolar - differ only from Santome, which does not have these vowels. The divergences among phoneme tables reflect the paths taken by the four languages from PGG speciation after the geographical separation of their speakers and the consequent formation of each language.
\end{abstract}

Keywords: portuguese-based creoles; Gulf of Guinea; phonology; comparison.

\section{Introdução}

Este estudo propõe uma análise comparativa das fonologias das quatro línguas da região do golfo da Guiné, a saber: o santome ${ }^{3}$ (ST) ou forro; o lung'le (LI) ou principense; o angolar (AN) ou ngola e o fa d'Ambô (FA), anobonense ou pagalu. O santome e angolar - ambos falados em São Tomé -, o lung'le - utilizado na ilha do Príncipe - e o fa d'Ambô - empregado mormente na ilha de Ano Bom - são línguas autóctones da região insular do golfo da Guiné, na África Ocidental. A formação dessas línguas está diretamente relacionada a uma língua ancestral que surge - no período de colonização portuguesa em São Tomé - a partir do contato entre colonizadores (lusofalantes) e populações africanas (multilíngues) transplantadas. Da necessidade de um código de comunicação, emerge, por conseguinte, uma língua de base lexical portuguesa, o protocrioulo do Golfo da Guiné4 (GÜNTHER, 1973; FERRAZ, 1979; SCHANG, 2003; HAGEMEIJER, 2009, 2011, BANDEIRA, 2017).

Com a consolidação do PGG, inicia-se, na sequência, a separação geográfica de seus falantes que, por um lado, são transplantados da ilha e, por outro, permanecem com os colonos ou escapam dos engenhos, formando comunidades de quilombos. Uma

\footnotetext{
3 A grafia dos nomes das línguas obedece ao padrão sugerido pelo Alfabeto Unificado para as Línguas Nativas de São Tomé e Príncipe (ALUSTP).
}

4 Conhecido como 'são tomense' (FERRAZ, 1979) ou 'língua de São Tomé'. 
parcela dos transplantados vai em direção à ilha do Príncipe, onde o PGG se desenvolveu, tornando-se o lung'le; outro fragmento populacional, por seu turno, é levado à ilha de Ano Bom, na qual, de modo semelhante, o PGG se especia, ramificando-se em fa d'Ambô. Em São Tomé, por sua vez, falantes do protocrioulo se distribuem entre aqueles que ficaram nos núcleos de colonização, onde surge o santome, ao passo que a comunidade quilombola se torna o berço da especiação do PGG em angolar (BANDEIRA, 2017). Desse modo, tendo em vista o parentesco genético das quatro línguas-filhas do PGG, o presente estudo pretende comparar os seus sistemas fonológicos, o que possibilitará verificar os aspectos em que essas línguas se assemelham e em quais, de igual modo, as mesmas divergem entre si.

Em vista disso, o estudo é apresentado da seguinte maneira: a seção 2 discute brevemente aspectos gerais acerca das línguas que são o objeto do estudo. Na seção 3 , demonstramos os materiais e métodos utilizados para a consecução da pesquisa. $\mathrm{Na}$ seção 4, é apresentada a análise dos dados. Na sequência, são expostas as considerações finais.

\section{As línguas autóctones do golfo da Guiné}

No que tange à sua gênese, o surgimento do santome está intrinsecamente relacionado à formação de uma nova sociedade com reivindicações e poderes socio-econômicos próprios durante a fase de habitação quando, em 1515 e 1517, o rei Dom Manuel declarou livres as escravas dadas aos portugueses, assim como os seus filhos (HLIBOWICKAWEGLARZ, 2012). Essa comunidade de forros muito provavelmente estava presente na origem e consolidação da nova língua falada na ilha (HAGEMEIJER, 2009).

Quanto à ocupação do espaço atual de São Tomé e Príncipe, The World Factbook estima que cerca de $61 \%$ da população ocupe as aglomerações urbanas, enquanto 39\% vive na zona rural (FACTBOOK, 2009). Essa distribuição sinaliza que a parcela majoritária populacional, ao estar inserida em contexto urbano, estaria mais exposta às influências do português, língua oficial do país e principal veículo de comunicação nesses locais. Além da urbanização, outro fator que condiciona o uso do português, em detrimento do santome, está relacionado à aprendizagem do santome como língua materna. Embora o santome esteja na posição de língua mais falada, entre as línguas autóctones, tem sido cada vez mais reduzido o número de pessoas que o aprendem como primeira língua. No entanto, o santome é a língua autóctone que desfruta de maior prestígio no país, sendo a língua de identidade do grupo étnico forro. No interior de São Tomé, ainda é muito usada além de ser associada aos costumes tradicionais do grupo forro e empregada em canções tradicionais são-tomenses. Quanto ao status do santome, Lorenzino (1996, p. 4) afirma que: "o seu prestígio deve-se por ter sido a língua dos mestiços que atingiram um influente status socio-económico quando converteram-se em proprietários de terras e escravos". Atualmente, o santome é a língua, depois do português, que possui mais 
falantes em São Tomé e Príncipe. Do total absoluto de 173.015 habitantes, 62.707 declaram ser proficientes em santome ${ }^{5}$ (INE, 2013).

No que se refere ao cenário linguístico referente ao lung'le, o PGG, já constituído, foi levado da ilha de São Tomé para o Príncipe no início do século XVI (HLIBOWICKAWEGLARZ, 2012). Com a separação e o posterior isolamento, resultado do deslocamento para a ilha do Príncipe, somado ao aporte de novo material linguístico proveniente das levas de escravos enviados diretamente à ilha, houve condições para o desenvolvimento independente do lung'le. Por ter sido isolado desde muito cedo, de acordo com Hagemeijer (2009), conjectura-se que, do ponto de vista do léxico e da fonologia, o lung'le seja a língua do grupo que mais apresenta léxico de origem edo e o que mais reteve aspectos fonológicos ${ }^{6}$ edóides, exclusivos da área onde essas línguas eram faladas.

Por ter um número reduzido de falantes, em torno de 1753 de acordo com o censo (INE, 2013) e, entre 20 a 30 pessoas, conforme estima Maurer (2009), o lung'le é considerado uma língua ameaçada (GÜNTHER, 1973; MAURER, 2009). Para Maurer (2009), a epidemia da doença do sono (tripanossomíase), por volta de 1900, pode ser caracterizada como o ponto de partida para o declínio da população falante do lung'le. Segundo Günther (1973) e Maurer (2009), tal epidemia teve um impacto muito significativo no desenvolvimento demográfico do Príncipe, haja vista que apenas 300 pessoas sobreviveram. Essa redução populacional, associada a outras demandas de mão de obra, levou as autoridades coloniais a importar trabalhadores contratados, primeiramente das colônias portuguesas, tais como, Angola e Moçambique, e, posteriormente, de São Tomé e especialmente das ilhas de Cabo Verde.

No que tange à origem da comunidade dos angolares em São Tomé, há três hipóteses concorrentes (SEIBERT, 2004). A primeira hipótese, de origem popular e difundida dentre a população local, formulada no século XIX, defende que os angolares são descendentes dos sobreviventes de um naufrágio de um navio de escravos oriundo de Angola em meados do século XVI. A segunda hipótese alega que os angolares seriam habitantes autóctones de São Tomé e, por essa razão, já estariam presentes na ilha no momento em que os portugueses ali aportaram. Por fım, a terceira hipótese (hipótese dos quilombolas) advoga que os ascendentes dos angolares eram antigos escravos que fugiram para áreas até então inabitadas, construindo uma nova comunidade, posteriormente ampliada com elementos dos recém-fugidos das roças e das cidades, por volta dos séculos XVI e XVII.

50 censo de 2011 não oferece dados sobre o bilinguismo ou o multilinguismo, sem definir também se cada língua contabilizada é falada como primeira ou segunda língua.

6 Tal afirmação demanda ponderação, posto que, sem um estudo fonológico sobre as línguas edóides, não é possível ter certeza sobre essas supostas peculiaridades linguísticas do grupo edo. Ademais, Ladhams (2007) sugere uma diversidade étnica maior nos primeiros anos formativos do PGG. 
Ferraz (1974) é um dos principais defensores da terceira hipótese. O primeiro argumento no qual o autor se baseia é o fato de que os angolares não falavam uma língua da família bantu, mas uma língua de base lexical portuguesa. O segundo ponto diz respeito à questão de como os angolares poderiam falar um crioulo baseado em itens lexicais portugueses, embora vivessem em isolamento do resto da população durante tanto tempo, como alegado, sobretudo, pela primeira hipótese. A partir de pesquisas de comparações genéticas entre as três línguas, Ferraz (1974) mostra que o angolar está relacionado linguisticamente com o santome e o lung'le, descartando as hipóteses de naufrágio e de que os angolares já habitavam São Tomé antes de os portugueses chegarem. Ferraz (1974) formula então a tese de que os escravos fugidos foram expostos às fases formativas do protocrioulo. Com o isolamento dos angolares, houve a especiação da língua, surgindo o angolar.

Os falantes do angolar vivem, hoje, nas zonas do litoral de São Tomé, no distrito de Caué, entre Ribeira Afonso até Porto Alegre e, no litoral noroeste, a partir de Neves até Bindá, no distrito de Lembá, e ademais, próximos à cidade de São Tomé, existem pequenos grupos de falantes em São João da Vargem, Pantufo e Praia Melão (CEITA, 1991). Para fins de análise, a pesquisa tem como objeto de investigação o angolar falado na comunidade de São João dos Angolares, uma pequena vila do distrito Caué. Estima-se que sua população local seja de 6.887 habitantes (INE, 2013). Atualmente, de acordo com os resultados do último censo realizado no país, da população absoluta (173.015), 11.377 são falantes do angolar, representando uma parcela de cerca de 6\% da população (INE, 2013).

Por fim, o fa d'Ambô é falado sobretudo em Ano Bom (Annobón em espanhol), uma pequena ilha de $17,2 \mathrm{~km}^{2}$, pertencente à República da Guiné Equatorial, situada ao sudoeste da ilha de São Tomé. A data da chegada dos europeus a Ano Bom é fonte de dissenso. Segorbe (2007) afirma que a descoberta da ilha ocorreu em 1471 por navegadores portugueses. Para Caldeira (2010), o descobrimento da ilha se deu em um primeiro de janeiro, o dia do Ano Novo ou do Ano Bom. Embora não seja possível, a partir de fontes fidedignas, estabelecer o ano exato da chegada dos portugueses à ilha de Ano Bom, Caldeira situa o evento entre 1493 e 1501. Segundo Araujo et al. (2013), em 1503, Jorge de Melo se tornou o primeiro capitão-donatário da ilha e responsável pela primeira povoação da ilha conforme o modelo de colonização portuguesa do começo do século XVI. Contudo, segundo Caldeira (2006), os colonizadores só chegariam em Ano Bom em 1543. As razões para essa demora na colonização se devem a diversos aspectos, tais como, a pequena extensão territorial da ilha, o relevo montanhoso que deixava poucas áreas férteis cultiváveis, ainda a falta de ancoradouros seguros, sua posição longe das rotas comerciais portuguesas e, por fim, a forte concorrência com a ilha de São Tomé (CALDEIRA, 2007, 2010).

Atualmente, a população de falantes do fa d'Ambô é de aproximadamente 5.600 , sendo cerca de 5 mil da Ilha de Ano Bom, e 600 distribuídos entre a capital Malabo, em outros 
lugares da Guiné Equatorial Continental e na Espanha (ARAUJO et al., 2013). Apresentado um breve histórico das quatro línguas autóctones do golfo da Guiné, na seção seguinte, serão demonstrados os procedimentos metodológicos empregados para a análise.

\section{Materiais e métodos}

O corpus deste estudo é resultado da reunião de cognatos realizada por Bandeira (2017), a partir de um conjunto de itens pertencentes ao léxico básico das quatro línguas-filhas do PGG. Para tal constituição, foram utilizados estudos teóricos, dicionários e gramáticas do santome; do lung'le, do angolar e do fa d'Ambô. No tocante aos materiais disponíveis mais antigos sobre as línguas-filhas, há estudos elaborados no século XIX sobre o santome (NEGREIROS, 1895), lung'le (RIBEIRO, 1888) e fa d'ambô (BARRENA, 1957), além de fontes esparsas como Schuchardt $(2008,1889,1888,1882)$ e Adolfo Coelho (1880).

Como os trabalhos publicados antes da segunda metade do século XX, em geral, apresentaram limitações descritivas e incongruências na notação dos dados, bem como na análise dos sistemas fonológicos das línguas, utilizamos, como base, dados linguísticos contemporâneos, coletados em trabalho de campo, e recolhidos de diferentes fontes (FERRAZ, 1979, 1987; MAURER, 1995, 2009; SEGORBE, 2007; HAGEMEIJER, 2009, 2011; ARAUJO; HAGEMEIJER, 2013; ARAUJO et al., 2013; ARAUJO; AGOSTINHO, 2015; AGOSTINHO, 2016; BANDEIRA, 2017). Além disso, foram consultadas informações disponibilizadas (on-line) pelo Atlas of Pidgin and Creole Language Structures (MICHAELIS et al., 2013). Além da consulta aos materiais existentes, foram realizadas três viagens de campo para São Tomé e Príncipe em que foram feitas gravações dos dados, permitindo confirmar a pronúncia e o significado dos vocábulos, bem como conhecer melhor as fonologias das línguas em estudo.

Feita a coleta, iniciou-se a etapa de análise dos itens, começando a partir do conjunto de cognatos que, nas quatro línguas-filhas, eram idênticos ou similares, ressalvadas todas as modificações ocorridas na evolução das línguas - situação nem sempre comum na análise dos dados. Adiante, foi dado início à especificação da posição dentro de um item lexical (inicial, medial, final) para as consoantes e vogais que estavam sendo comparadas. Ademais, foi preciso confirmar se os reflexos distintos ocorrem em ambientes idênticos ou, por outro lado, os mesmos estão em distribuição complementar com alguma outra unidade de som. Em conjunto com a seleção de cognatos, realizou-se também a análise do sistema fonêmico das línguas-filhas quanto aos seus aspectos convergentes e divergentes. A partir das descrições previamente realizadas, foram feitas análises a fim de confirmar ou refutar esses estudos prévios.

Após a reunião dos dados das quatro línguas, foram selecionados os itens do corpus a partir de um vocabulário básico comum. A escolha pelo léxico básico se deve, seguindo Fox (1995), à tentativa de evitar o problema de se trabalhar com itens resultados de 
empréstimo. Em vista disso, o vocabulário básico seria mais propenso a ser herdado do que nativizado via empréstimo. Na primeira etapa da análise, formou-se um corpus com um conjunto de cognatos - itens com equivalência semântica e fonética. Para tanto, a análise se guiou através do princípio da regularidade das correspondências recorrentes entre os fonemas das línguas-filhas (KAUFMAN, 1990; HOCK, 1991; CROWLEY, 1997[1992]; CAMPBELL, 2004[1998]). A partir dos conjuntos de correspondências fonológicas extraídas, foram constituídos grupos de cognatos. Desse modo, reunimos 536 cognatos com cerca de 2000 itens no total para a análise - o conjunto dos dados analisados pode ser consultado em Bandeira (2017). Assim, o estudo se baseia nas fonologias das línguas-filhas e na análise de 536 conjuntos de palavras com significados equivalentes reunidos por Bandeira (2017).

\section{Análise dos dados}

Nessa seção, será feita uma comparação de alguns aspectos fonológicos do santome, fa d'Ambô, lung'le e angolar. Antes de dar início à comparação das quatro línguas, serão apresentados alguns pares mínimos que justificam a proposição dos fonemas nas quatro línguas (BANDEIRA, 2017) - para uma discussão mais detalhada dos quadros fonológicos do santome, fa d'Ambô, lung'le e angolar, consultar Bandeira (2017).

Quadro 1. Alguns pares mínimos do santome

\begin{tabular}{|c|c|c|c|}
\hline $\begin{array}{c}\text { [pa 'pa] 'pai, papai' } \\
\text { [ba'ba] 'laço' }\end{array}$ & $\begin{array}{l}\text { ['tazi] 'tarde' } \\
\text { ['dazi] 'idade' }\end{array}$ & 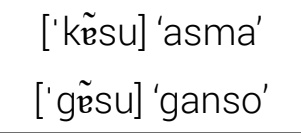 & $\begin{array}{l}\text { ['lẽmu] 'ramo' } \\
\text { ['Iẽenu] 'ranho' }\end{array}$ \\
\hline $\begin{array}{c}\text { [ka'na] 'acanhar' } \\
\text { [ka'na] 'cana de } \\
\text { açúcar' }\end{array}$ & $\begin{array}{l}\text { ['ola] 'hora' } \\
\text { ['ока] 'orelha' }\end{array}$ & $\begin{array}{l}\text { [fle'ga] 'esfregar' } \\
\text { [vle'ga] 'curvar' }\end{array}$ & $\begin{array}{c}\text { ['sa] 'assar' } \\
\text { ['za] 'já' }\end{array}$ \\
\hline $\begin{array}{l}\text { [' Ja] 'cheio' } \\
\text { ['za] 'dia' }\end{array}$ & $\begin{array}{l}\text { ['saka] 'bolsa' } \\
\text { ['zaka] 'jaca' }\end{array}$ & $\begin{array}{c}\text { ['tfi] 'tio' } \\
\text { ['dzil] preposição }\end{array}$ & $\begin{array}{c}{\left[{ }^{\prime} \varepsilon\right]^{\prime} \operatorname{sim}^{\prime}} \\
{\left[\text { 'e] } 3^{a} \text { p. do singular }\right.}\end{array}$ \\
\hline $\begin{array}{l}\text { ['pitu] 'apito' } \\
\text { ['petu] 'peito' }\end{array}$ & $\begin{array}{c}\text { ['po] 'árvore' } \\
\text { ['po] 'ser capaz de' }\end{array}$ & $\begin{array}{l}\text { [ku'je] 'colher' } \\
\text { [ko'je] 'escolher' }\end{array}$ & $\begin{array}{c}\text { [ka'sa] 'caçar' } \\
\text { [ka'so] 'cachorro' }\end{array}$ \\
\hline
\end{tabular}

Fonte: Exemplos retirados de Bandeira (2017) 
Quadro 2. Alguns pares mínimos do fa d'Ambô

\begin{tabular}{|c|c|c|c|}
\hline $\begin{array}{c}\text { [o'po] 'pó' } \\
\text { [o'bo] 'adiante' }\end{array}$ & $\begin{array}{c}\text { ['te] 'ter' } \\
\text { ['de] preposição }\end{array}$ & $\begin{array}{l}\text { [fu'ka] 'afogar' } \\
\text { [fu'ga] 'julgar' }\end{array}$ & $\begin{array}{l}\text { ['ga:se] 'garça' } \\
\text { ['ba:se] 'balsa' }\end{array}$ \\
\hline $\begin{array}{l}\text { ['masv] 'manso' } \\
\text { ['basv] 'abaixo' }\end{array}$ & $\begin{array}{l}\text { ['nẽse] 'arte de } \\
\text { pescar' } \\
\text { ['dẽse] 'dança' }\end{array}$ & $\begin{array}{c}\text { ['la:] 'errar' } \\
\text { ['Ka:] 'aprisionar' }\end{array}$ & 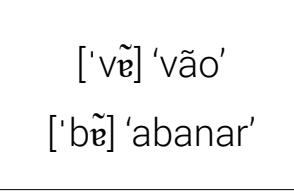 \\
\hline $\begin{array}{l}\text { ['fato] 'pouco' } \\
\text { ['vato] 'inquieto' }\end{array}$ & $\begin{array}{c}\text { ['salø] 'sal' } \\
\text { ['zalø] 'gole de } \\
\text { bebida' }\end{array}$ & $\begin{array}{c}{\left[p \tilde{\varepsilon}^{\prime} d e\right] \text { 'pender' }} \\
\text { [pẽ'de] 'extraviar- } \\
\text { se' }\end{array}$ & $\begin{array}{l}\text { ['mol] 'mouro' } \\
\text { ['mol] 'amor' }\end{array}$ \\
\hline $\begin{array}{l}\text { ['kato] 'quatro' } \\
\text { ['kato] 'navalha' }\end{array}$ & $\begin{array}{l}\text { [a'la] 'lá' } \\
\text { [a'le] 'rei' }\end{array}$ & $\begin{array}{l}\text { [ku'sa] 'sarna' } \\
\text { [ku: 'sa] 'cruzar' }\end{array}$ & $\begin{array}{c}\text { ['vidu] 'visto' } \\
\text { ['vi:du] 'ponto de } \\
\text { vista' }\end{array}$ \\
\hline
\end{tabular}

Fonte: Exemplos retirados de Bandeira (2017)

Quadro 3. Alguns pares mínimos do lung'le

\begin{tabular}{|c|c|c|c|}
\hline $\begin{array}{l}\text { ['pikv] 'pico' } \\
\text { ['bikv] 'bico' }\end{array}$ & $\begin{array}{l}{[\text { 'tof } \mathrm{f}] \text { 'pino' }} \\
{\left[\text { 'd } \iint_{\mathrm{I}}\right] \text { 'sino' }}\end{array}$ & 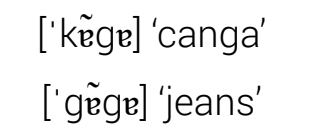 & $\begin{array}{c}\text { [u'ka] 'ocá' } \\
\text { [u'kpa] 'lampião' }\end{array}$ \\
\hline $\begin{array}{l}\text { ['ba] 'aonde' } \\
\text { ['gba] 'ordenar' }\end{array}$ & $\begin{array}{l}\text { ['mame] 'mãe' } \\
\text { ['mane] 'irmã' }\end{array}$ & $\begin{array}{l}\text { [pa'na] 'apanhar' } \\
\text { [pa'na] 'aplainar' }\end{array}$ & $\begin{array}{c}\text { [ra'la] 'ralar' } \\
\text { [la'la] 'lá' }\end{array}$ \\
\hline $\begin{array}{l}\text { ['male] 'mala' } \\
{[\text { 'maKe] 'malha' }}\end{array}$ & $\begin{array}{c}\text { ['fa] partícula de } \\
\text { negação } \\
\text { ['va] 'descascar' }\end{array}$ & $\begin{array}{l}\text { [ka'sa] 'caçar' } \\
\text { [ka'za] 'casar' }\end{array}$ & $\begin{array}{l}\text { ['Ja] 'chá' } \\
\text { ['za] 'já' }\end{array}$ \\
\hline $\begin{array}{l}\text { [o'po] 'pó' } \\
{\left[\jmath^{\prime} p \varepsilon\right] \text { 'pé' }}\end{array}$ & $\begin{array}{l}\text { [ma 'do] 'esperto' } \\
\text { [ma'de] 'útero' }\end{array}$ & $\begin{array}{c}\text { ['ba] 'cadê, onde } \\
\text { está?' } \\
\text { ['ba:] 'arder' }\end{array}$ & $\begin{array}{c}\text { ['ni] 'aqui' } \\
\text { ['ni:] 'nenhum' }\end{array}$ \\
\hline
\end{tabular}

Fonte: Exemplos retirados de Bandeira (2017) 
Quadro 4. Alguns pares mínimos do angolar

\begin{tabular}{|c|c|c|c|}
\hline $\begin{array}{l}\text { [pa'ga] 'pagar' } \\
\text { [ba'ga] 'quebrar' }\end{array}$ & $\begin{array}{c}\text { [kõ'te] 'odiar' } \\
\text { [kõ' de] 'esconder' }\end{array}$ & $\begin{array}{l}\text { [ji 'ka] 'empurrar' } \\
\text { [ji'ga] 'chegar' }\end{array}$ & 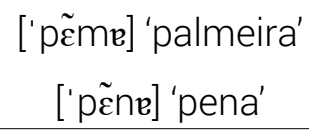 \\
\hline $\begin{array}{c}\text { [ku'ma] 'comadre' } \\
\text { [ku'na] 'cair, } \\
\text { machucar' }\end{array}$ & $\begin{array}{c}\text { ['lata] 'lata' } \\
\text { ['data] } \\
\text { 'quantidade' }\end{array}$ & $\begin{array}{c}\text { [f } \varepsilon^{\prime} \text { ga] 'esfregar' } \\
\text { [ve'ga] 'levar' }\end{array}$ & $\begin{array}{l}\text { ['vale] 'vara' } \\
\text { ['bale] 'bala' }\end{array}$ \\
\hline $\begin{array}{c}\text { ['Өa] 'estar' } \\
\text { ['ða] 'já' }\end{array}$ & $\begin{array}{l}\text { ['fake] 'faca' } \\
\text { ['ðake] 'jaca' }\end{array}$ & $\begin{array}{c}\text { [tẽ 'ba] 'tamba (peixe)' } \\
{\left[\mathrm{t} \tilde{\mathrm{e}}^{\prime} \mathrm{b} \varepsilon\right] \text { 'também' }}\end{array}$ & $\begin{array}{l}\text { ['me] 'metade' } \\
\text { ['me] 'mesmo' }\end{array}$ \\
\hline $\begin{array}{l}\text { [lo' lo] 'lamber' } \\
\text { [lo 'lo] 'dor' }\end{array}$ & $\begin{array}{l}\text { ['vi] 'vinho' } \\
\text { ['ve] 'vez' }\end{array}$ & $\begin{array}{c}\text { ['e] } 3^{a} \text { p. do singular } \\
\text { ['e:] 'sim' }\end{array}$ & $\begin{array}{c}\text { ['kusv] 'peso de } \\
\text { areia' } \\
\text { ['ku:sv] 'cruz' }\end{array}$ \\
\hline
\end{tabular}

Fonte: Exemplos retirados de Bandeira (2017)

Para a análise comparativa, primeiramente, verificaremos os quadros vocálicos, em seguida, os quadros consonantais. Ao longo dos quadros a seguir, o símbolo (x) indicará presença e o sinal tracejado (---) indicará ausência do segmento ou da estrutura na referida língua.

\section{Vogais e consoantes}

Os segmentos vocálicos de cada fonologia foram comparados. Os sistemas de vogais orais simples convergem em todos os pontos (Cf. quadros 5 e 6), ao passo que os sistemas de vogais longas - idênticos em fa d'Ambô, em lung'le e em angolar - diferem apenas do santome que não apresenta os referidos segmentos.

Quadro 5. Comparação dos sistemas vocálicos das línguas-filhas - vogais simples

\begin{tabular}{|c|c|c|c|c|}
\hline & /i u/ & /e o/ & /ع o/ & /a/ \\
\hline Santome & $x x$ & $x x$ & $x x$ & $x$ \\
\hline Fa d'ambô & $x x$ & $x x$ & $x x$ & $x$ \\
\hline Lung'le & $x x$ & $x x$ & $x x$ & $x$ \\
\hline Angolar & $x x$ & $x x$ & $x x$ & $x$ \\
\hline
\end{tabular}

Fonte: Bandeira (2017) 
Quadro 6. Comparação dos sistemas vocálicos das línguas-filhas - vogais longas

\begin{tabular}{|c|c|c|c|c|}
\hline & /ii uu/ & /ee oo/ & 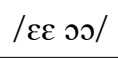 & /aa/ \\
\hline Santome & ---- & --- & --- & --- \\
\hline Fa d'ambô & $x x$ & $x x$ & $x x$ & $x \times$ \\
\hline Lung'le & $x x$ & $x x$ & $x x$ & $x x$ \\
\hline Angolar & $x x$ & $x x$ & $x x$ & $x x$ \\
\hline
\end{tabular}

Fonte: Bandeira (2017)

No que concerne às consoantes, por seu turno, nos quadros 7 e 8, estão dispostos, para fins de comparação, os pontos convergentes e divergentes entre os inventários das quatro línguas-filhas que compartilham treze fonemas consonantais, a saber: /p b t d $\mathrm{kg} \mathrm{f} v \mathrm{I} \mathrm{m} n \mathrm{w} \mathrm{j} / \mathrm{e}$ divergem, outrossim, em relação à presença ou à ausência de treze consoantes: /kp gb s z $\theta \partial \int 3 \kappa \mathrm{rt} \int \mathrm{d} 3 \mathrm{n} /$.

Quadro 7. Comparação dos sistemas consonantais das línguas-filhas - semelhanças

\begin{tabular}{|l|l|l|l|l|l|l|l|}
\hline & $/ \mathrm{p} \mathrm{b} /$ & $/ \mathrm{t} \mathrm{d} /$ & $/ \mathrm{kg} /$ & $/ \mathrm{f} \mathrm{v} /$ & $/ / /$ & $/ \mathrm{m} \mathrm{n} /$ & $/ \mathrm{w} \mathrm{j} /$ \\
\hline Santome & $\mathrm{xx}$ & $\mathrm{xx}$ & $\mathrm{xx}$ & $\mathrm{xx}$ & $\mathrm{x}$ & $\mathrm{xx}$ & $\mathrm{xx}$ \\
\hline Fa d'Ambô & $\mathrm{xx}$ & $\mathrm{xx}$ & $\mathrm{xx}$ & $\mathrm{xx}$ & $\mathrm{x}$ & $\mathrm{xx}$ & $\mathrm{xx}$ \\
\hline Lung'le & $\mathrm{xx}$ & $\mathrm{xx}$ & $\mathrm{xx}$ & $\mathrm{xx}$ & $\mathrm{x}$ & $\mathrm{xx}$ & $\mathrm{xx}$ \\
\hline Angolar & $\mathrm{xx}$ & $\mathrm{xx}$ & $\mathrm{xx}$ & $\mathrm{xx}$ & $\mathrm{x}$ & $\mathrm{xx}$ & $\mathrm{xx}$ \\
\hline
\end{tabular}

Fonte: Bandeira (2017)

Quadro 8. Comparação dos sistemas consonantais das línguas-filhas - divergências

\begin{tabular}{|c|c|c|c|c|c|c|c|c|}
\hline & /s z/ & $/ \int 3 /$ & / $\theta$ ठ/ & $/ \mathrm{t} \int \mathrm{d}_{3} /$ & $/ r /$ & $/ K /$ & $/ \mathrm{n} /$ & /kp gb/ \\
\hline Santome & $x x$ & $x x$ & --- & $x x$ & --- & $x$ & $x$ & --- \\
\hline Fa d'Ambô & $x x$ & --- & --- & --- & --- & $x$ & --- & --- \\
\hline Lung'le & $x x$ & $x x$ & --- & --- & $x$ & $x$ & $x$ & $x x$ \\
\hline Angolar & --- & --- & $x x$ & --- & --- & --- & $x$ & --- \\
\hline
\end{tabular}

Fonte: Bandeira (2017) 
No quadro 8, comparativamente, o conjunto de fricativas é o que mais apresenta discordância. Nesse sentido, o par de pós-alveolares $/ \int 3 /$ é um ponto que divide as quatro línguas em dois grupos: o primeiro grupo que apresenta as fricativas (santome e lung'le) e o grupo que não as apresenta (angolar e fa d'Ambô) como fonemas. Em santome e lung'le, as consoantes / $/ \mathrm{J} / \mathrm{e} / 3 /$ não possuem suas realizações condicionadas a quaisquer contextos. Em fa d'Ambô, por seu turno, as consoantes [f] e [3] foram registradas como alofones de /s/ e /z/, cujas realizações estiveram circunscritas à proximidade com a vogal /i/ ou com a aproximante /j/ como em (01) e (02) (exemplos retirados de Bandeira, 2017).

(01) /teesi/ ['te:fI] 'três' (fa d'Ambô)

(02) /boNdazi/ [bõ' dazi] 'bondade' (fa d'Ambô)

O angolar, por sua vez, não apresentou as consoantes pós-alveolares como alofones. Assim, além de não apresentar as fricativas mencionadas, o angolar não possui as consoantes /s/ e /z/. Em contrapartida, o angolar apresenta fricativas interdentais / $\theta$ / e /ð/, exclusivas à língua, sendo que, diante de /i/ e de /j/, tais consoantes se realizam foneticamente como [s] e [z], respectivamente como nos exemplos de (03) a (06) (exemplos retirados de Bandeira, 2017).

/piөipi/ ['pisipi] 'príncipe' (angolar)

(04) /bieidu/ [bi'sido] 'vestido' (angolar)

(05) /mbeði/ ['mbezi] 'lua' (angolar)

(06) /kuðja/ [ku'zja] 'cozinha' (angolar)

Ainda sobre as divergências, o santome foi a única língua a apresentar as consoantes africadas/t $\mathrm{f} / \mathrm{e} / \mathrm{d}_{3} /$ como fonemas (Cf. exemplos 07 e 08) (exemplos retirados de Bandeira, 2017). Nas demais línguas, é possível observar a realização de [t]] e [d3] condicionada aos contextos em que as consoantes /t/ e /d/ antecediam /i/ e /j/ (Cf. exemplos 0911) (exemplos retirados de Bandeira, 2017). Muito possivelmente as africadas foram introduzidas à fonologia do santome em um período posterior à ramificação da protolíngua.

(07) ['mot fe] 'entrar em transe' (santome)

(08) ['dzagv] 'aziago' (santome) 
(09) [so 'tfi] 'açoite' (lung'le)

(10) ['mot $\left.\int \mathrm{I}\right]$ 'morte' (angolar)

(11) ['tadzI] 'tarde' (fa d'Ambô)

Nos conjuntos das laterais e das nasais, enquanto o angolar não apresentou a consoante $/ K /$, presente nas demais línguas, o fa d'Ambô não exibiu a consoante /n/ como fonema. No cotejo dos dados, no momento em que todas as línguas exibiam a lateral palatal, o angolar apresentou duas consoantes alternantes: /j/ ou /// (exemplos retirados de Bandeira, 2017).

(12) ['zuko] 'julho' (santome) - ['zulo] 'julho' (angolar)

(13) ['guke] 'agulha' (fa d'Ambô) - ['guje] 'agulha' (angolar)

O fa d'Ambô, por sua vez, apenas exibiu o segmento [n] como alofone, restringindo-se ao contexto de adjacência à vogal /i/ e à consoante /j/ como em (14). Nos outros contextos, a língua apresentou a consoante /j/ quando as demais línguas apresentavam o fonema /n/ como em (15) (exemplos retirados de Bandeira, 2017).

(14) /ineni/ [i'neni] possessivo de $3^{a}$ pessoa do plural (fa d'Ambô)

(15) ['zũno] (santome) - ['zũno] (lung'le) - ['dũno] (angolar) - ['zujo] (fa d'Ambô) 'junho'

No conjunto de róticos, o lung'le foi a única língua do cluster que apresentou uma vibrante /r/ que pode ocorrer apenas na primeira posição do onset em início e meio de palavra, nunca como coda ou como segundo elemento de um onset complexo (exemplos retirados de Bandeira, 2017).

(16) [ra'la] 'ralar' (lung'le)

(17) ['rjadv] 'desanimado' (lung'le)

O elemento rótico também é registrado em português e nas línguas de substrato edo, mas não se encontra nas línguas bantu ocidentais. A presença da vibrante em lung'le foi influenciada não só pelo português, língua lexificadora, mas também pelas línguas edóides. Pode-se supor que o lung'le foi uma das primeiras línguas a ser ramificada do PGG, posto que, com a saída de parte de falantes do protocrioulo para a Ilha do Príncipe, 
houve, por conseguinte, a ramificação da língua. Tal separação remontou ao período pré-bantu em São Tomé. Como o impacto linguístico bantu foi mais reduzido na Ilha do Príncipe do que em São Tomé, o lung'le apresentou condições favoráveis no que tange à preservação dos traços linguísticos da camada mais antiga de origem edo (Cf. HAGEMEIJER, 2011).

Com o intuito de analisar os motivos para a presença das consoantes velolabiais, exclusivas ao lung'le, é necessário considerar as características da língua de substrato das quatro línguas-filhas, sobretudo do grupo linguístico com o qual o lung'le supostamente apresentaria mais semelhanças tipológicas. Historicamente, o comércio de escravos para São Tomé, no final dos séculos XV e XVI, possuiu como alvo duas principais áreas tipologicamente distintas: o Delta do Níger e a região do bantu Ocidental (LADHAMS, 2007; CALDEIRA, 2008; HAGEMEIJER, 2011). Segundo Hagemeijer (2011), os crioulos de base portuguesa do golfo da Guiné apresentam transferência e sobreposição de camadas desses dois diferentes estratos. Quanto às velo-labiais, tais fonemas seriam tipologicamente marcados e constituiriam um traço areal da região que abrange clusters nigerianos, relacionados às línguas do grupo edo (CLEMENTS; RIALLAND, 2008; GÜLDEMANN, 2008). As consoantes velo-labiais são atestadas em algumas línguas bantu do norte, mas não na zona que inclui o cluster congo e quimbundo, logo não se pode atribuir a presença dessas consoantes às línguas da região banto do Congo-Angola, mas ao substrato das línguas edóides das línguas-filhas. A razão pela qual apenas o lung'le manteve as velo-labiais reside no fato de que, de acordo com Hagemeijer (2011), o lung'le foi umas das primeiras línguas a ser ramificada do PGG, remontando ao período pré-bantu em São Tomé. Assumindo que o impacto bantu foi mais restrito à Ilha do Príncipe do que em São Tomé, o lung'le apresentou as melhores condições de preservar características linguísticas da camada mais antiga de origem do Delta do Níger (referentes às línguas do grupo edo) (HAGEMEIJER, 2011). No Quadro 9, notam-se as semelhanças lexicais entre os itens de etimologia edo sobretudo com o lung'le (AGHEYISI, 1990; MAURER, 2009; HAGEMEIJER, 2011).

Quadro 9. kp e gb em comparação - adaptado de Hagemeijer (2011, p. 117)

\begin{tabular}{|l|l|l|l|l|l|}
\hline Glosa & Edo & Lung'le & Santome & Fa d'Ambô & Angolar \\
\hline "grão" & Ikpe & {$\left[i^{\prime} k p \varepsilon\right]$} & [u'kwe] & [i'ku] & [i'kwe] \\
\hline "tipo de cerca" & Ogba & ['ugba] & ['ubwa] & ['ubulu] & ['ubwa] \\
\hline "corpo" & Ègbé & [i'gbe] & ['ubwe] & [o'ge:] & [o'ge] \\
\hline "bochecha" & Agbanwen & [u'gbami] & [u'bwami] & [o'gomu] & ---- \\
\hline
\end{tabular}

Fonte: Bandeira (2017) 
A semelhança entre os cognatos no Quadro 9 sugere que o santome, fa d'Ambô e angolar interpretaram as velo-labiais como oclusivas simples, apagando alguns de seus traços. Somado a isso, em lung'le, única língua do cluster a apresentar as consoantes, o grupo de palavras com as consoantes complexas tem se reduzido a menos de uma dezena. Assim, esses étimos e suas velo-labiais possivelmente circulavam no ambiente do protocrioulo, talvez em variação com suas contrapartes oclusivas simples, mas foram alteradas por forças internas a cada uma das línguas, exceto no lung'le que, por ter um afluxo edóide por mais tempo, optou por manter elementos como as velo-labiais em variação.

\section{Considerações finais}

Neste estudo, foram cotejados alguns pontos convergentes e divergentes das quatro línguas autóctones do golfo da Guiné no que diz respeito aos quadros vocálicos e consonantais. Em linhas gerais, pode-se dizer que as sete vogais orais simples estão presentes nas quatro línguas, ao passo que as sete vogais longas se encontram em três das quatro línguas: fa d'Ambô, lung'le e angolar. Na comparação dos inventários consonantais, todas as línguas compartilham treze fonemas (/p b t d k g f v I m n w j/) e divergem, de maneira análoga, quanto a treze fonemas (/kp gb s z $\theta$ ə $3 \kappa \mathrm{rt} \int \mathrm{d} z \mathrm{n} /$ ).

As divergências entre os quadros de fonemas refletiram os caminhos tomados pelas quatro línguas. Caminhos esses cujas explicações podem ser encontradas nos diferentes cenários de especiação do PGG após a separação geográfica de seus falantes. Nesse sentido, o lung'le e o fa d'Ambô foram transplantados da ilha de São Tomé, ao passo que o angolar, fruto da especiação do PGG dentro de uma comunidade quilombola, desenvolveu-se com menos pressões do elemento luso e implementado com um certo aporte bantu. Por conseguinte, as três línguas, embora tenham se desenvolvido separadamente, apresentaram muitos pontos semelhantes entre si, a exemplo das vogais longas idênticas. Em contrapartida, as mencionadas línguas também refletiram aspectos fonológicos distintos, relacionados aos contextos socio-históricos de suas formações. 0 lung'le, em virtude de sua maior proximidade com as línguas do grupo edóide, apresenta em seu inventário consoantes exclusivas, tais como, as velo-labiais $/ \mathrm{kp} \mathrm{gb} / \mathrm{e}$ a vibrante $/ r /$. O fa d'Ambô, por seu turno, talvez por ter sido a língua do cluster que, por mais tempo, manteve-se apartado de colonizadores e imigrantes em geral, apresentou um registro maior de alongamento vocálico, comparativamente, em contextos aos quais o lung'le e o angolar foram mais refratários. O angolar, se por um lado se une ao fa d'ambô e ao lung'le ao apresentar vogais longas, por outro, isola-se completamente ao exibir consoantes fricativas interdentais $/ \theta$ ð/. Por sua vez, o santome - que surgiu do protocrioulo falado nos centros de colonização - foi o único integrante do cluster a apresentar consoantes africadas / $\mathrm{t} \int \mathrm{d} z /$, provavelmente, devido ao contato com o português - ante a sua maior proximidade com lusofalantes. 


\section{REFERÊNCIAS}

AGHEYISI, R. A grammar of Edo. Unesco, 1990.

AGOSTINHO, A. Fonologia do Lung'le. Lincom Studies in Pidgin \& Creole Linguistics 15. Muenchen: LINCOM GmbH, 2016.

ARAUJO, G.; AGOSTINHO, A. L. Fa do Vesu, a language game of Fa d'Ambô. PAPIA, São Paulo, v. 24, n. 2, p. 265-281, 2014.

ARAUJO, G. et al. Fa d'ambô: língua crioula de base portuguesa de Ano Bom. Cadernos de Estudos Linguísticos, v. 55, n. 2, p. 25-44, 2013.

ARAUJO, G.; HAGEMEIJER, T. Dicionário Santome-Português/Português-Santome. São Paulo: Hedra, 2013.

BANDEIRA, M. Reconstrução fonológica e lexical do protocrioulo do Golfo da Guiné. 2017. Tese (Doutorado em Filologia e Língua Portuguesa) - Faculdade de Filosofia, Letras e Ciências Humanas, Universidade de São Paulo, São Paulo, 2017.

BARRENA, N. Gramatica anobonesa. Madrid: Instituto de Estudios Africanos, 1957.

CALDEIRA, A. Uma ilha quase desconhecida. Notas para a história de Ano Bom. Africana Studia, v. 17, p. 99-109, 2006.

CALDEIRA, A. La leyenda de lodã, o de cómo rolando, compañero del emperador Carlomagno, defendió la isla de Annobón de una invasión terrible. Oráfrica, v. 6, p. 89-114, 2010.

CALDEIRA, A. Medo e religião popular na ilha de Ano Bom. Uma aproximação histórica (séculos XVI-XIX). 2008. Disponível em: http://cvc.instituto-camoes.pteaarcoloquio comunicacoes. Acesso em: 12 set. 2014.

CALDEIRA, A. Crenças religiosas e ritos mágicos na ilha de Ano Bom: uma aproximação histórica. Povos e Culturas, v. 11, p. 87-111, 2007.

CAMPBELL, L. Historical linguistics: an introduction. Edinburgh: Edinburgh University Press, 2004 [1998]. 
CEITA, M. N. Ensaio para uma Reconstrução Histórico-Antropológica dos angolares de S. Tomé. 1991. Trabalho de Conclusão de Curso (Pós-graduação em Desenvolvimento Social e Económico em África) - Centro de Estudos Africanos, Instituto Universitário de Lisboa, Lisboa, 1991.

CLEMENTS, G. N.; RIALLAND, A. Africa as a phonological area. In: HEINE, B.; NURSE, D. (ed.). A linguistic geography of Africa. Cambridge: Cambridge University Press, 2008. p. 3685.

COELHO, F. A. Os dialetos românticos ou neolatinos na África, Ásia e América. Boletim da Sociedade de Geografia de Lisboa. 2. série, v. 3. Lisboa: Academia Internacional da Cultura Portuguesa, 1880. p. 129-196.

CROWLEY, T. An introduction to historical linguistics. Auckland: Oxford University Press, 1997 [1992].

FACTBO0K, C. 2009. Disponível em: https://www.cia.gov/library/publications/the-worldfactbook/geos/tp.html. Acesso em: 20 maio 2013.

FERRAZ, L. I. Portuguese creoles of West Africa and Asia. In: GILBERT, G. (ed.). Pidgins and creole languages: essays in memory of John E. Reinecke. Honolulu: University of Hawaii Press, 1987. p. 337-360.

FERRAZ, L. I. The creole of São Tomé. Johannesburg: Witwatersrand University Press, 1979.

FERRAZ, L. I. A Linguistic Appraisal of Angolar. Memoriam Antônio Jorge Dias, v. 2, p. 177186, 1974.

FOX, A. Linguistic reconstruction: an introduction to theory and method. Oxford: Oxford University Press, 1995.

GÜLDEMANN, T. The macro-Sudan belt: Towards identifying a linguistic area in northern sub-Saharan African. In: HEINE, B.; NURSE, D. (ed.). A linguistic geography of Africa. Cambridge: Cambridge University Press, 2008. p. 151-185.

GÜNTHER, W. Das Portugiesische Kreolisch der ilha do Príncipe. Marburgo: Marburg an der Lahn, 1973. 
HAGEMEIJER, T. Initial vowel agglutination in the Gulf of Guinea creoles. In: ABOH, E.; SMITH, N. (ed.). Complex processes in new languages. Amsterdam/Filadélfia: John Benjamins Publishing Company, 2009. p. 29-50.

HAGEMEIJER, T. The Gulf of Guinea Creoles: Genetic and typological relations. Journal of Pidgin and Creole Languages, v. 26, n. 1, p. 111-154, 2011.

HLIBOWICKA-WEGLARZ, B. A origem dos crioulos de base lexical portuguesa no Golfo da Guiné. Romanica Cracoviensia, v. 11, p. 177-185, 2012.

HOCK, H. H. Initial strengthening. In: DRESSLER, W. U.; LUSCHÜTZKY, H. C.; PFEIFFER, O. E.; RENNISON, J. R. (ed.). Phonologica 1988: Proceedings of the 6th International Phonology Meeting. Cambridge: Cambridge University Press, 1991. p. 101-110.

INE. Recenseamento Geral da População e da Habitação: Características Educacionais da População. São Tomé: INE, 2013.

KAUFMAN, T. Language history in South America: what we know and how to know more. In: PAYNE, D. (ed.). Amazonian Linguistics. Austin: University of Texas Press, 1990. p. 13-31.

LADHAMS, J. Article Agglutination and the African Contribution to the Portuguese-based Creoles. 2007. Disponível em: http://bit.ly/2BTPbZL. Acesso em: 20 out. 2016.

LORENZINO, G. A. Uma avaliação socio-linguística sobre São Tomé e Príncipe. Actas do Congresso Internacional sobre o Português, v. II, p. 1-17, 1996.

MAURER, P. L'Angolar: Un créole afroportugais parlé à São Tomé; Notes de grammaire, textes, vocabulaires. Hamburg: Helmut Buske Verlag, 1995.

MAURER, P. Principense. Grammar, texts, and vocabulary of the Afro-Portuguese creole of the Island of Príncipe, Gulf of Guinea. London: Battlebridge Publications, 2009.

MICHAELIS, S. M. et al. Atlas of Pidgin and Creole Language Structures Online. Leipzig: Max Planck Institute for Evolutionary Anthropology, 2013. Disponível em: http://apicsonline.info. Acesso em: 6 set. 2015.

NEgREIROS, A. L de A. História Etnographica da Ilha de S.Tomé. Lisboa: Antiga Casa Bertrand, 1895. 
RIBEIRO, M. F. Dialecto da ilha do Principe. MS número 11.23.12, Schuchardt Archive da Universidade de Graz, Áustria, 1888.

SCHANG, E. L'emergence des créoles portugais du golfe de Guinée. 2003. Tese (Doutorado em Linguística) - Atelier nacional de reproduction des thèses, Université Nancy 2, Nacy, 2003.

SCHUCHARDT, H. On the creole portuguese of São Tomé (West Africa). Annotated translation from the German of Ueber des Negerportugiesische von S. Thomé. Sitzungsberichte Wien, v. 101, n. 2, p. 889-917. In: HAGEMEIJER, T.; HOLM, J. (ed.). Contact Languages: Critical Concepts in Linguistics. v. 1. London, New York: Routledge, 2008 [1882]. p. 131-156.

SCHUCHARDT, H. Ueber das Negerportugiesische der Ilha do Príncipe. Zeitschrift für romanische Philologie, v. 13, p. 463-475, 1889.

SCHUCHARDT, H. Ueber das Negerportugiesische von Annobom. Sitzungsberichte Wien, v. 116, p. 193-226, 1888.

SCHUCHARDT, H. Ueber des Negerportugiesische von S. Thomé. Sitzungsberichte Wien, v. 101, n. 2, p. 889-917, 1882.

SEGORBE, A. Gramática descriptiva del fa d'ambô. Barcelona: CEIBA Ediciones, 2007.

SEIBERT, G. Os angolares da Ilha de São Tomé: Náufragos, Autóctones ou Quilombolas? Dossiê História Atlântica, v. 12, n. 1/2, p. 43-64, 2004. 